\title{
Formation of ZSM-5 on Silicon Carbide Fibers for
}

\section{Catalytic Support}

\author{
Yoon-joo Lee ${ }^{1}$, Dong-geun Shin ${ }^{2 *}$, Younghee Kim ${ }^{1}$, Woo-teck Kwon ${ }^{1}$, Soo-ryong Kim ${ }^{1}$ and Doh-hyung Riu ${ }^{3}$ \\ 1. Energy Materials Center, Korea Institute of Ceramic Engineering and Technology, 101, Soho-ro, Jinju-si, Gyeongsangnam-do \\ 52851, Korea \\ 2. Ceramic Fiber \& Composite Center, Korea Institute of Ceramic Engineering and Technology, 101, Soho-ro, Jinju-si, \\ Gyeongsangnam-do 52851, Korea \\ 3. Department of Materials Science and Engineering, Seoul National University of Science and Technology, 172 Gongreung 2-dong, \\ Nowon-gu, Seoul 139-743, Korea
}

\begin{abstract}
ZSM-5 crystals were grown on the SiC fiber surface which was prepared by melt-spinning of polycarbosilane, silicon based preceramic polymer. To improve the bonding property between ZSM-5 crystals and $\mathrm{SiC}$ fiber, $200 \mathrm{~nm}$ of $\mathrm{SiO}_{2}$ layer was formed on the fiber surface by simple oxidation before hydrothermal reaction in the autoclave because it was compositionally similar to ZSM-5 and relatively easy to form on the SiC fiber. During the process, $1 \mu \mathrm{m}$ of zeolite crystals were very uniformly grown on the fiber surface. Weak X-ray diffraction (XRD) peaks observed between $10^{\circ}$ and $30^{\circ}$ showed that crystal structure of them were accorded to ZSM-5 structure. They were broken away with SiC fiber support during fracture test which mean that they were strongly bonded to fiber surface. This type of $\mathrm{SiC}$ based catalysts are expected for high-temperature gas-phase reaction, especially strong acid base conditions.
\end{abstract}

Key words: Zeolite, ZSM-5, SiC fiber, catalyst support, energy efficiency.

\section{Introduction}

Zeolites are the crystalline aluminosilicate which have porous microstructure. It has been used as catalysts for petrochemical cracking, molecular sieves and ion exchangers and expanded to clean environment and renewable energy such as production of bio-fuel in fixed bed reactors in the forms of granules or pellets [1-3]. These trends are demanding the improvement of catalytic efficiency. However, several drawbacks caused by application method makes it hard to maintain the catalysis efficiency and reproducibility during process and limit a wide industrial application: (i) loss of catalyst, (ii) low thermal conductivities, (iii) limited mass transport rates, (iv) fouling by carbon residue $[4,5]$.

*Corresponding author: Dong-geun Shin, Ph.D., senior researcher, research fields: ceramic fiber matrix composites (CMCs), SiC fiber, preceramic polymer and catalyst support.
During the past decades, some investigations have been paid attention to the development of zeolite coatings on various support materials such as porous glass monolith [6], alumina [7], metals [8] and porous ceramics [9, 10]. Among those materials, silicon carbide ( $\mathrm{SiC}$ ) appears as a valuable candidates as zeolite support due to its differentiated intrinsic properties such as high thermal conductivity, excellent chemical/oxidation resistance. $\mathrm{P}$. Losch et al. demonstrated the growth of zeolite on $\mathrm{SiC}$ monolith with additional Si-source [10]. Kim et al. explained the effect of SiC crystal phase on growing ZSM-5 on $\mathrm{SiC}$ powder and foam [11]. Actually, SiC has been used to just abrasive materials for a long time and it changes its face to advanced ceramics, recently. It is used to the parts for semiconductor after sintering, single crystal and wafer for high power semiconductor for electric car and $\mathrm{SiC}_{\mathrm{f}} / \mathrm{SiC}$ composites for various high-temperature applications [12-15]. However, pore 
size and structure of $\mathrm{SiC}$ should be controlled for catalytic support application. There are several processes to make porous SiC. Replica is general method that mother foam such as polyurethane or graphite foam is pyrolyzed to $\mathrm{SiC}$ foam just after loading Si and C mixed slurry or polycarbosilane, the preceramic polymer [16, 17]. Extrusion can make honeycomb type porous $\mathrm{SiC}$ using SiC slurry [18]. Fiber mat process has been newly interested because of its high specific surface area, thermal conductivity and flexibility [19]. It can be obtained in the form of woven or nonwoven mat based on preceramic polymer technology. However, ZSM-5 is basically different from $\mathrm{SiC}$ in composition and crystal structure included lattice parameter. Therefore, the surface of the $\mathrm{SiC}$ fiber itself was needed to be modified for heterogeneous growth of ZSM-5 with good adhesion as shown in Fig. 1.

In this study, $\mathrm{SiC}$ fibers which $1 \mu \mathrm{m}$ size of ZSM-5 crystals were uniformly distributed on the fiber surface were investigated by controlling the thermal oxidation and hydrothermal synthesis condition, and their microstructural evolution with formation behavior were also discussed.

\section{Experimental Setup}

\subsection{Preparation of SiC Fiber Support}

$\mathrm{SiC}$ fiber was prepared by melt spinning of polycarbosilane (PCS) and pyrolysis [20-22]. PCS fiber was obtained using a melt spinning apparatus with a spinneret having $500 \mu \mathrm{m}$ single nozzle under the argon gas pressure. The continuous green fibers were produced at spinning temperatures between 160 and $250{ }^{\circ} \mathrm{C}$, and winding speeds up to $500 \mathrm{rpm}$ [21]. The green fibers were cured to make an infusible fiber through the thermal oxidation which were introduced the oxygen onto the fiber surface and made a cross-link among PCS molecules. Then, the cured fibers were heat-treated at $1,200{ }^{\circ} \mathrm{C}$ for $1 \mathrm{~h}$ in an argon atmospheric graphite furnace to $\mathrm{SiC}$ fibers. Prior to ZSM-5 coating, SiC fibers were oxidized at the temperature between 800 and $1,400{ }^{\circ} \mathrm{C}$ in the atmospheric muffle furnace to make $\mathrm{SiO}_{2}$ layer before the growth of ZSM-5 on the surface.

\subsection{Heterogeneous Formation of ZSM-5}

ZSM-5 was synthesized by the hydrothermal reaction in an autoclave. Tetraethyl orthosilicate (TEOS, 98\%, Sigma Aldrich) and aluminum nitrate nonahydrate $\left(\mathrm{Al}\left(\mathrm{NO}_{3}\right) \cdot 9 \mathrm{H}_{2} \mathrm{O},>98 \%\right.$, Sigma Aldrich) were used as source materials, and tetrapropylammonium hydroxide (TPAOH, $1.0 \mathrm{M}$ in $\mathrm{H}_{2} \mathrm{O}$, Sigma Aldrich) was added for the template of ZSM-5. TEOS, TPAOH and $\mathrm{Al}\left(\mathrm{NO}_{3}\right) \cdot 9 \mathrm{H}_{2} \mathrm{O}$ were mixed in molar ratio of $1.0: 1.5: 0.03$ in $\mathrm{H}_{2} \mathrm{O}$ in the teflon-lined stainless steel autoclave $(100 \mathrm{ml})$. Then, $\mathrm{SiC}$ fibers, the substrate material, were loaded before autoclave reaction at $180-220{ }^{\circ} \mathrm{C}$ for $1-10 \mathrm{~h}$. It was undergone the first and second calcination at $550{ }^{\circ} \mathrm{C}$ for $10 \mathrm{~h}$ after washing and freeze drying. Finally, $\mathrm{SiC}$ fibers were taken out of the vessel and washed out using ultrasonic cleaner to remove residual zeolite powder.

\subsection{Characterization}

Samples were characterized using field-emission

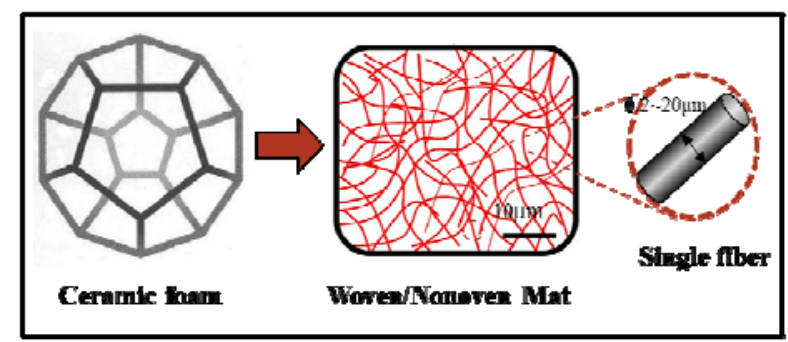

I. changing highly flexible and high specific surface support

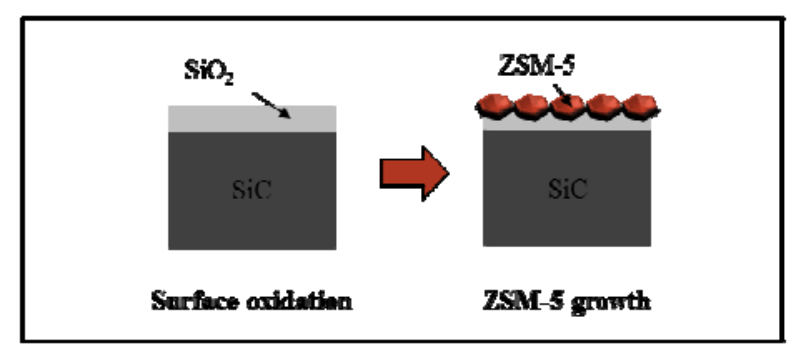

IL. Surface modification for strong bonding each other

Fig. 1 Strategic approach for high performance catalyst system. 
scanning electron microscopy (FE-SEM, JEOL, JSM-6700F), X-ray diffraction (XRD, P/MAX 2200V/PC, Rigaku Corp., Cu target, $\mathrm{K} \alpha=1.54 \AA$ ), thermo-gravimetric analysis (TGA, TGA/SDTA 851, Mettler Toledo) and BET analysis (ASAP 2010, Micromeritics).

The crystal phases and their shapes were determined after chopping and crushing of the as-synthesized sample. The tensile strength of $\mathrm{SiC}$ fibers before and after surface oxidation at $1,200{ }^{\circ} \mathrm{C}$ for $1 \mathrm{~h}$ and after ZSM-5 growth on the fiber surface was measured by a single filament tensile test method (ASTM D 3379) with $30 \mathrm{~mm}$ gauge length using universal test machine (Instron 4204, Instron, USA).

\section{Results and Discussion}

3.1 Growth of ZSM-5 on SiC Fiber without Surface Oxidation

ZSM-5 was homogeneously grown without catalyst support at the same condition for heterogeneous growth on catalyst support to confirm the growth condition of ZSM-5. Fig. 2 shows the FE-SEM image of ZSM-5 crystals which were synthesized by hydrothermal reaction at $180{ }^{\circ} \mathrm{C}$ for $1 \mathrm{~h}$. Hexagonal shape of ZSM-5 crystals were grown well and their size were around $1 \mu \mathrm{m}$ and the specific surface area was $277 \mathrm{~m}^{2} / \mathrm{g}$ which was analyzed by BET method. This value was reasonable for zeolite, generally. The crystal structure was confirmed by the comparison of the X-ray diffraction patterns as shown in Fig. 3.

The diffraction peaks were detected at $7.9^{\circ}, 8.9^{\circ}$, $23.1^{\circ}, 24^{\circ}$ and $24.5^{\circ}$ corresponding to ZSM-5 that the molar ratio of $\mathrm{SiO}_{2}$ and $\mathrm{Al}_{2} \mathrm{O}_{3}$ is 30 (JCPDS No. 44-0003). This pattern indicates that the synthesis condition was suitable for forming $1 \mu \mathrm{m}$ size of ZSM-5 crystals uniformly.

Based on the result, ZSM-5 was directly grown on the $\mathrm{SiC}$ fiber without any surface treatment. Before growing ZSM-5, surface and cross-section of the bare $\mathrm{SiC}$ fiber were very clean and dense without any pores or defect although any cleaning steps were performed.
Fig. 4 shows the low/high magnification FE-SEM images of SiC fibers growing ZSM-5 at the same synthetic condition with Fig. 2. ZSM-5 crystals were

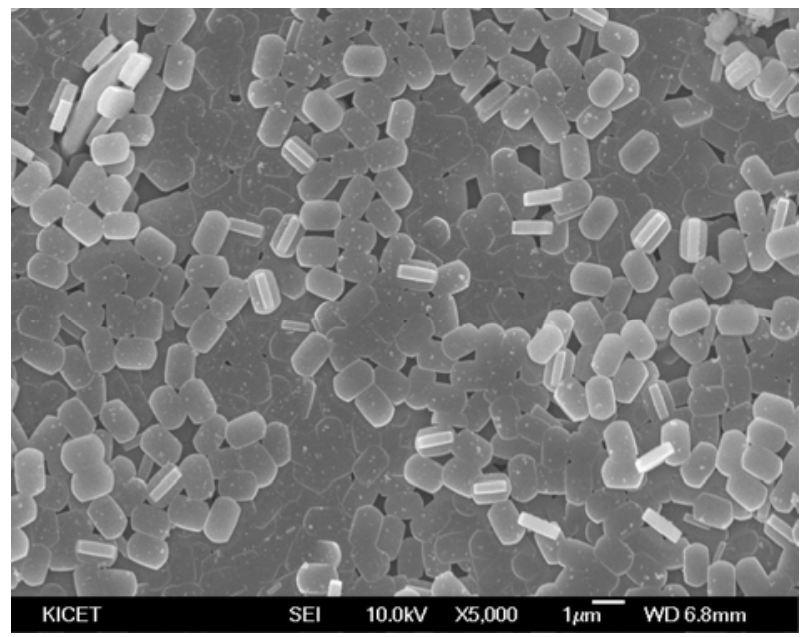

Fig. 2 FE-SEM image of ZSM-5 crystals which were synthesized by hydrothermal reaction at $180^{\circ} \mathrm{C}$ for $1 \mathrm{~h}$.

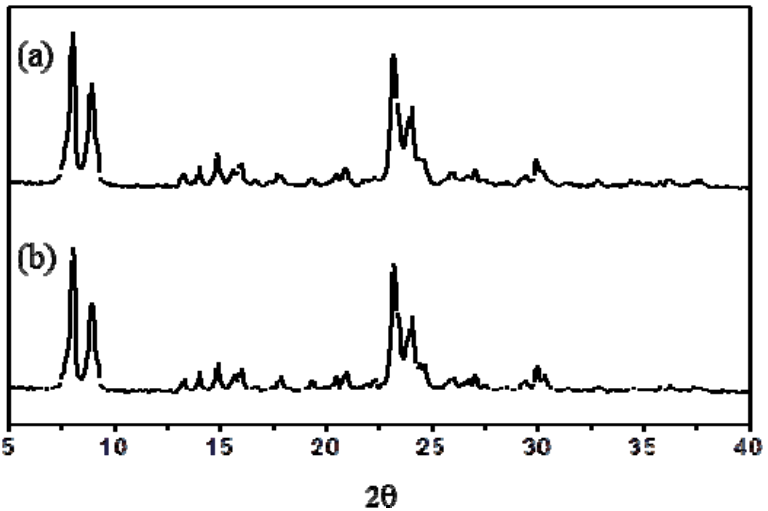

Fig. 3 FE-SEM image of ZSM-5 crystals which were synthesized by hydrothermal reaction at $180^{\circ} \mathrm{C}$ for $1 \mathrm{~h}$.
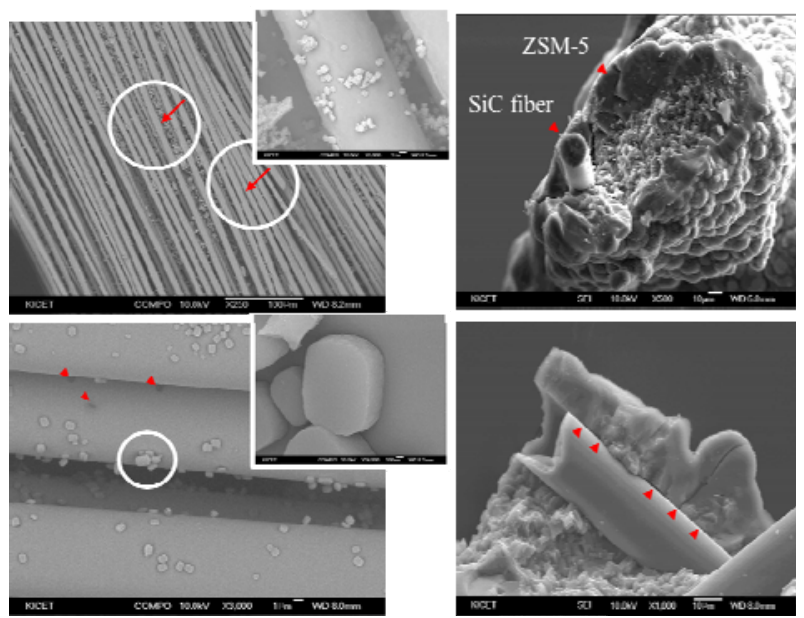

Fig. 4 Low/high magnification FE-SEM images of SiC fiber growing ZSM-5 at $180{ }^{\circ} \mathrm{C}$ for $1 \mathrm{~h}$. 
agglomerated among fibers and some were observed on the fiber. However, they were easily leaved away from the surface during simple preparation steps which means that they just stay on the surface and there were no chemical interactions.

We increased the concentration of source materials to make thick ZSM-5 coating layer on the surface. However, there were also no interaction between $\mathrm{SiC}$ fiber and ZSM-5 layer at the interface even though very thick ZSM-5 layer covered whole fiber surface (see Figs. $4 c$ and $4 d$ ). It means that some surface modification or buffer layer should be constructed between them to make strong chemical bonding and grow ZSM-5 crystals on the surface with stable.

\subsection{Growth of ZSM-5 on SiC Fiber without Surface Oxidation}

$\mathrm{SiO}_{2}$ was selected to the buffer layer because it was ease to make dense $\mathrm{SiO}_{2}$ layer on the $\mathrm{SiC}$ fiber through simple oxidation and compositionally similar to ZSM-5. Okamura et al. and other previous study confirmed that $\mathrm{SiO}_{2}$ oxidation layer having $\alpha$-cristobalite of crystal phase was formed during oxidation above $1,000^{\circ} \mathrm{C}$, which was act as protection layer [21-24]. The formation mechanism of $\mathrm{SiO}_{2}$ on the $\mathrm{SiC}$ fiber is followed by simple reaction equation depending on the oxidation temperature and time:

$$
\mathrm{SiC}+2 \mathrm{O}_{2} \rightarrow \mathrm{SiO}_{2}+\mathrm{CO}_{2}
$$

(i) Diffusion of oxygen to the fiber surface, (ii) diffusion through the $\mathrm{SiO}_{2}$ film, (iii) chemical reaction at the interface, (iv) diffusion of carbon dioxide through the $\mathrm{SiO}_{2}$ film and (v) diffusion of carbon dioxide to the gas phase.

Fig. 5 shows the oxidation behavior of $\mathrm{SiC}$ fiber with different oxidation temperature and time. Color of the fibers was changed with oxidation condition as shown in the optical microscope images. Blue color was observed when it oxidized at $1,000{ }^{\circ} \mathrm{C}$ for $24 \mathrm{~h}$ and $1,200{ }^{\circ} \mathrm{C}$ for $1 \mathrm{~h}$, and it was changed with oxidation time at $1,200^{\circ} \mathrm{C}$. On the other hand, optical images obtained at $1,400{ }^{\circ} \mathrm{C}$ oxidation condition show mixed colors of the sample.

Cross-sectional SEM image of the samples in Fig. 6 showed (a) $300 \mathrm{~nm}$ of thin and uniform $\mathrm{SiO}_{2}$ layer at $1,200{ }^{\circ} \mathrm{C}$ and (b) very thick and irregular layer with crack or bubble penetration at $1,400{ }^{\circ} \mathrm{C}$. If $\mathrm{SiO}_{2}$ layer are thick enough, $\mathrm{CO}$ bubble can make channels and crack also can be formed during cooling step due to thermal expansion difference [23].

Fig. 6 shows FE-SEM images of $\mathrm{SiC}$ fiber with growing ZSM-5. When oxidized at $1,000{ }^{\circ} \mathrm{C}$ for $2 \mathrm{~h}$ (Fig. 6a), ZSM-5 crystals were observed on the surface

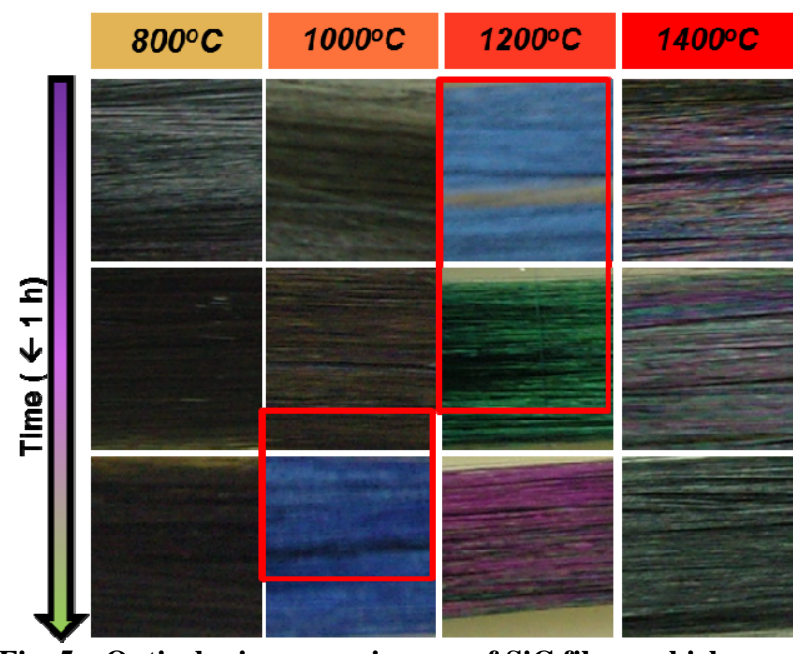

Fig. 5 Optical microscope images of SiC fibers which were oxidized at $800-1,400{ }^{\circ} \mathrm{C}$ for $1-24 \mathrm{~h}$.
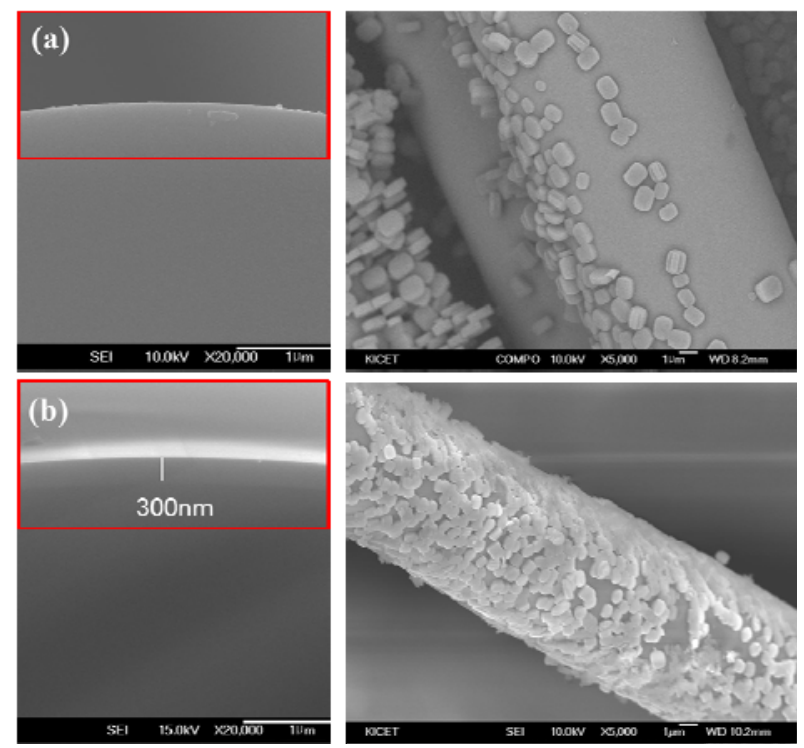

Fig. 6 FE-SEM images of SiC fibers growing ZSM-5 after oxidation at (a) $1,000{ }^{\circ} \mathrm{C}$ for $2 \mathrm{~h}$ and (b) $1,200{ }^{\circ} \mathrm{C}$ for $2 \mathrm{~h}$. 


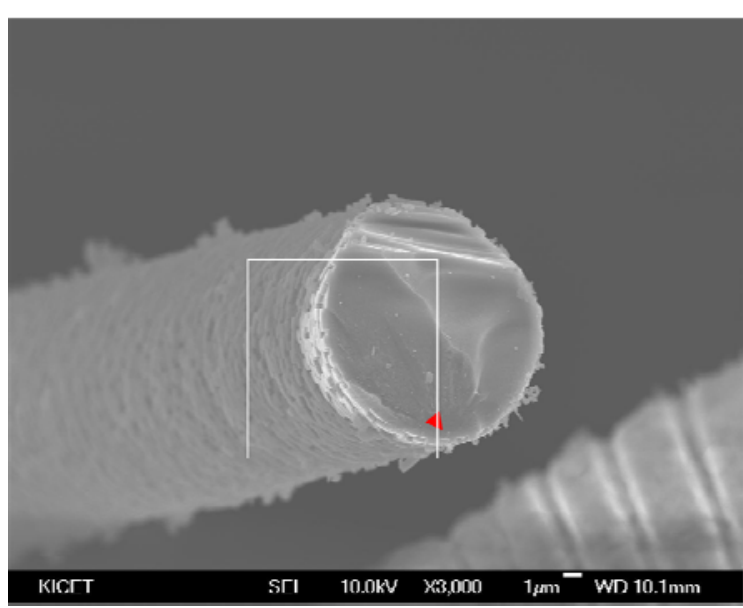

(a)

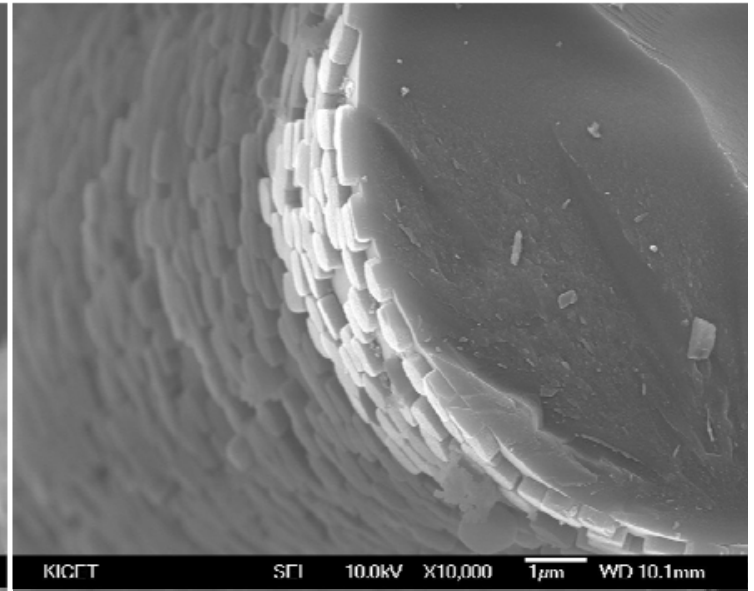

(b)

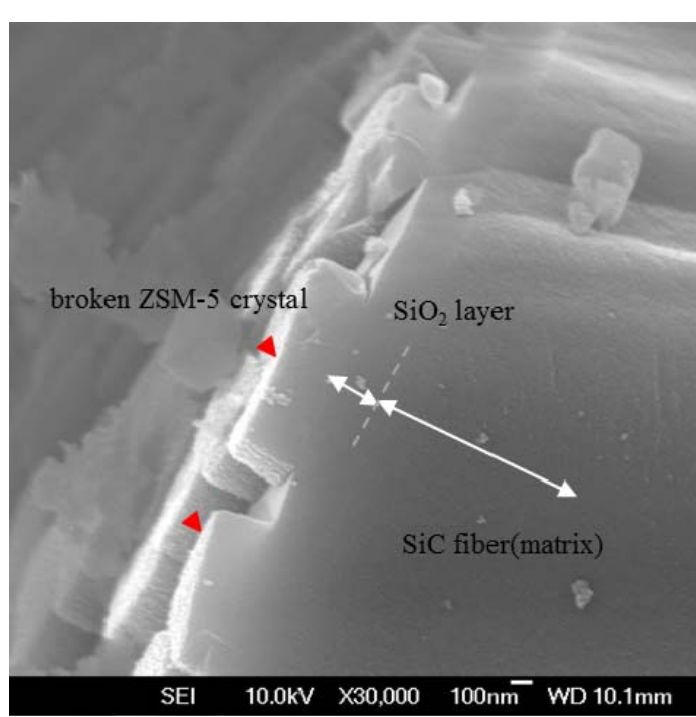

(c)

Fig. 7 (a-c) Low/high magnificence of the fractured SiC fiber after single filament tensile test (ASTM D-3379).

but they were not uniform and agglomeration also observed in places. It was expected that very thin oxidation layer would be formed and affect the growth of ZSM-5 although oxidation layer was not observed in the SEM study.

However, there was no difference with the case of Figs. $4 \mathrm{a}$ and $4 \mathrm{~b}$. In case of oxidation at $1,200{ }^{\circ} \mathrm{C}$ for 2 h, ZSM-5 crystals were stably formed on the surface with good adhesion and very uniform on the whole fiber surface. It was closely related to the formation of $\mathrm{SiO}_{2}$ layer and their thickness although it would be needed further detailed study. These fibers were undergone single fiber tensile test. Sample fiber was chosen from bundle very carefully and glued on to paper tab with $30 \mathrm{~mm}$ of gauge length prepared from
ASTM-D 3379. The strength of the fiber was around 1.7 GPa similar to bare $\mathrm{SiC}$ fiber which means that there was no critical deterioration on the mechanical properties of SiC fiber after ZSM-5 growth. Fig. 7 shows the fracture image of the tensile test sample fiber. Fracture origin was existed on the interface between matrix fiber and $\mathrm{SiO}_{2}$ layer, and crack started at this point. The mirror/mist and hackle feature were clearly observed on the fracture surface. The fracture mirror is a smooth region adjacent to the initiating defect in the fiber and is surrounded by a region of multiple fracture planes [25]. At this point, crack didn't propagate along the interface but held the original propagation direction, perpendicular to fiber surface. Furthermore, ZSM-5 crystals also were 
broken away without any delamination which means that they have made very strong chemical bond between ZSM-5 crystals and matrix fiber.

\section{Conclusions}

ZSM-5 crystals were grown on the $\mathrm{SiC}$ fiber surface with stable which was oxidized for the formation of $300 \mathrm{~nm}$ of thin $\mathrm{SiO}_{2}$ layer as heterogeneous nucleation site at $1,200{ }^{\circ} \mathrm{C}$ for $2 \mathrm{~h}$. They were very uniformly formed on the fiber surface and very strongly bonded each other. It is expected that this type of nano-porous $\mathrm{SiC}$ fibers can be a potential candidate in catalyst and catalytic supports for harsh environmental application such as biomass conversion process.

\section{Acknowledgments}

This research was supported by the fundamental research program funded by the Civil Military Technology Cooperation (14-BR-MA-04) and by a grant from the $\mathrm{R} \& \mathrm{D}$ program funded by the Korea Institute of Ceramic Engineering and Technology.

\section{References}

[1] Cundy, C. S. and Cox, P. A. 2003. "The Hydrothermal Synthesis of Zeolites: History and Development from the Earliest Days to the Present Time." Chem. Rev. 103: 663-701.

[2] Hara, M., Nakajima, K. and Kamata. K. 2015. "Recent Progress in the Development of Solid Catalysts for Biomass Conversion into High Value-Added Chemicals." Sci. Technol. Adv. Mater. 16: 34903-25.

[3] Misaelides, P. 2011. "Application of Natural Zeolites in Environmental Remediation: A Short Review." Micropor. Mesopor. Mater. 114: 15-8.

[4] Jiao, Y., Jiang, C., Yang, Z., Liu, J. and Zhang, J. 2013. "Synthesis of Highly Accessible ZSM-5 Coatings on SiC Foam Support for MTP Reaction.” Micropor. Mesopor. Mater. 181: 201-7.

[5] Araki, T., Watanabe, K., Yoshida, T., Nishide, S., Masaki, S. and Ogasawara, T. 2002. "High Temperature Properties of $\mathrm{SiC}$ Fiber Reinforced $\mathrm{SiC}$ Matrix Composites for Turbine Rotor Application." Ceram. Eng. Sci. Proc. 23: 580-8.

[6] Louis, B., Ocampo, F., Yun, H., Tessonnier, J. P. and Pereira, M. M. 2010. "Hierarchical Pore ZSM-5 Zeolite
Structures: From Micro- to Macro-Engineering of Structured Catalysts." Chem. Eng. J. 161: 397-402.

[7] Puil, N., Dautzenberg, F. M., van Bekkum, H. and Jansen, J. C. 1999. "Preparation and Catalytic Testing of Zeolite Coatings on Preshaped Alumina Supports." Micropor. Mesopor. Mater. 27: 95-106.

[8] Yang, Z. and Yan, Y. 2001. "Synthesis of Highly $\beta$-Oriented Zeolite MFI Films by Suppressing Twin Crystal Growth during the Secondary Growth." Chem. Mater. 13: 1101-7.

[9] Zampieri, A., Mabande, G. T. P., Selvam, T., Schwieger, W., Rudolph, A. and Hermann, R. et al. 2006. "Biotemplating of Luffa Cylindrica Sponges to Self-Supporting Hierarchical Zeolite Macrostructures for Bio-Inspired Structured Catalytic Reactors." Mater. Sci. Eng. C 26: 130-5.

[10] Losch, P., Boltz, M., Soukup, K., Song, I. H., Yun, H. S. and Louis, B. 2014. "Binderless Zeolite Coatings on Macroporous $\alpha$-SiC Foams." Micropor. Mesopor. Mater. 188: 99-107.

[11] Jung, E., Lee, Y. J., Kim, Y., Kwon, W. T., Shin, D. G. and Kim, S. R. 2015. "Synthesis of ZSM-5 on the Surface of Foam Type Porous SiC Support." Korean Chem. Eng. Res. 53: 425-30.

[12] Naslain, R. 2004. "Design, Preparation and Properties of Non-Oxide CMCs for Applications in Engines and Nuclear Reactors: An Overview." Comp. Sci. Tech. 64: 155-70.

[13] Riccardi, B., Fenici, P., Frias Rebelo, A., Giancarli, L., Le Marois, G. and Philippe, E. 2000. "Status of the European R \& D Activities on $\mathrm{SiCf} / \mathrm{SiC}$ Composites for Fusion Reactors." Fusion Eng. \& Design 51-52: 11-22.

[14] Toshio, O. 2004. "Recent Research Activities Regarding SiC-Based Ceramic Composites for Aerospace Application.” J. Plasma \& Fusion Research 80: 36-41.

[15] Kaya, H. 1999. "The Application of Ceramic-Matrix Composites to the Automotive Ceramic Gas Turbine." Comp. Sci. Tech. 59: 861-72.

[16] Zhu, X., Jiang, D. and Tan, S. 2002. "Preparation of Silicon Carbide Reticulated Porous Ceramics." Mater. Sci. Eng. A 323: 232-8.

[17] Kim, Y. W., Wang, C. and Park, C. B. 2007. "Processing of Porous Silicon Oxycarbide Ceramics from Extruded Blends of Polysiloxane and Polymer Microbead." $J$. Ceram. Soc. Japan 115: 419-24.

[18] Guo, X., Cai, X., Zhu, L. and Yang, H. 2014. "Preparation and Pore Structure Characteristics of SiC Honeycomb Ceramics with Macroporous Walls." Ceram. Inter. 40: 6339-43.

[19] Shin, D. G., Cho, K. Y. and Riu, D. H. 2012. "A Porous $\mathrm{SiC}$ Mat for a Gas Radiation Application by Melt-Blown 
of the Polycarbosilane.” Asian J. Chem. 24: 4225-31.

[20] Shin, D. G., Riu, D. H., Kim, Y., Kim, H. R., Park, H. S. and Kim, H. E. 2005. "Characterization of SiC Fiber Derived from Polycarbosilanes with Controlled Molecular Weight." J. Korean Ceram. Soc. 42: 593-8.

[21] Shin, D. G., Kong, E. B., Cho, K. Y., Kwon, W. T., Kim, Y. and Kim, S. R. et al. 2013. "Nano-Structure Control of SiC Hollow Fiber Prepared from Polycarbosilane." $J$. Korean Ceram. Soc. 50: 3001-7.

[22] Shin, D. G., Cho, K. Y., Kim, Y., Kwon, W. T., Kim, S. R. and Lee, Y. J. et al. 2014. "Fabrication of Nanoporous Silicon Carbide Fibres by Thermal Treatment." Adv. Appl. Ceram. 113: 341-5.
[23] Shimoo, T., Morisada, Y. and Okamura, K. 2002. "Oxidation Behaviour of Si-M-C-O Fibers under Wide Range of Oxygen Partial Pressures." J. Mater. Sci. 37: 4361-8.

[24] Takeda, M., Saeki, A., Sakamoto, J., Imai, Y. and Ichikawa, H. 1999. "Oxidative Degradation Behavior of Polycarbosilane-Derived Silicon Carbide Fibers." Comp. Sci. Tech. 59: 787-92.

[25] Davies, I. J., Ishikawa, T., Shibuya, M. and Hirokawa, T. 1999. "Fibre Strength Parameters Measured in Situ for Ceramic-Matrix Composites Tested at Elevated Temperature in Vacuum and in Air." Comp. Sci. Tech. 59: 801-11. 